\title{
Applications of Ferroelectric Materials in the Field of Photovoltaics
}

\author{
Xinshu Luo, Shixin Xue, and Jingbo Zhang* \\ Key Laboratory of Inorganic-Organic Hybrid Functional Material Chemistry, Ministry of Education, \\ Tianjin Key Laboratory of Structure and Performance for Functional Molecules, College of Chemistry, \\ Tianjin Normal University, Tianjin 300387, China
}

Email: hxxyzjb@tjnu.edu.cn (J. Z.)

\begin{abstract}
To solve the severe energy shortages, a variety of photovoltaic devices such as silicon solar cells, inorganic thin film solar cells, perovskite solar cells, dye-sensitized solar cells, organic solar cells and quantum dot solar cells, have been developed for the utilization of solar energy. Major studies focus on how to improve the photovoltaic performance of these solar cells. Some of ferroelectric materials can be spontaneously polarized and have spontaneous polarization dipole moment inside at room temperature. Recently, some of ferroelectric materials are introduced in these solar cells due to their special properties. They can be used not only as light absorbing materials in ferroelectric solar cells, but also as functional materials due to their ferroelectric characteristic. The measurable macroscopic electric field can be formed inside ferroelectric materials film that can be used as built-in electric field for photovoltaic devices to separate electron-hole pairs and facilitate their transport. Therefore, the introduction of ferroelectric materials into several important solar cells can accelerate the transport rate of photogenerated electrons, thus the short-circuit photocurrent of the cells can be increased and the light-to-electric conversion efficiency is also effectively improved. In this minireview, we summarized the applications of ferroelectric materials in the field of photovoltaics to improve their photovoltaic performance.
\end{abstract}

Keywords ferroelectric materials, solar cells, spontaneous polarization, photovoltaic performance

\section{Introduction}

In recent decades, the demand of non-renewable fossil energy such as coal and oil has been quickly increased. The energy shortage has become an important factor restricting the economic development. Many countries are looking for new energy for the economic development. At this time, rich, clean and easy-to-obtain light energy shows its importance. Therefore, solar energy is regarded as the most promising energy source. ${ }^{[1-4]}$ At present, extensive researches are being carried out on the development of photovoltaic devices. The main types of solar photovoltaic devices include silicon solar cells, dye-sensitized solar cells, perovskite solar cells, organic thin film solar cells, copper indium gallium selenide solar cells etc. In the development of these photovoltaic devices, in order to prepare solar cells with lower cost and higher conversion efficiency, ferroelectric materials have attracted much attention due to their special photoelectric conversion mechanisms. ${ }^{[5-7]}$

In 1920, French Valasek discovered the ferroelectric effect in the rochelle salt, which opened the curtain for the study of ferroelectric materials. ${ }^{[8]}$ The ferroelectric thin films have an improved light response speed and a larger photo-generated current, thus improving the power conversion efficiency (PCE) of ferroelectric photovoltaic device. ${ }^{[9]}$ Therefore, the research on the photovoltaic properties of ferroelectric materials has gradually shifted from single crystals and ceramics to ferroelectric thin films. There are some crystals with ferroelectricity, which can be divided into four categories from the crystal structure of ferroelectric materials containing hydrogen bonds such as potassium dihydrogen phosphate $\left(\mathrm{KH}_{2} \mathrm{PO}_{4}\right)$, oxygen octahedrons, fluorine-containing octahedrons and other ionic groups. These four oxygencontaining octahedron ferroelectric materials are most used.
Among them, perovskite-type ferroelectric materials are more used and their structure is $\mathrm{ABO}_{3}$ such as $\mathrm{BaTiO}_{3}, \mathrm{BiFeO}_{3}$, and $\mathrm{PbTiO}_{3}$. In addition, the photovoltaic properties of $\mathrm{Pb}(\mathrm{Zr}, \mathrm{Ti}) \mathrm{O}_{3}$ ferroelectrics have also been mostly studied.

The properties of ferroelectric materials can be evaluated by the hysteresis loop (Figure 1). At the microscopic level, ferroelectric materials have many polarons with positive and negative centers that do not coincide, and polarons with the same direction gather together to form ferroelectric domains. When the voltage is applied, the domain of the polarization along the direction of the electric field is enlarged, and the polarization degree of the material becomes large as shown by the curve in the OA section. The polarization $(P)$ increases with the electric field $(E)$ to point $\mathrm{B}$, and $P$ changes linearly with $E$ (BC segment). When the electric field strength decreases, $P$ does not fall along the original curve, but decreases along the CBPr curve. When $E$ is zero, the polarization value is the

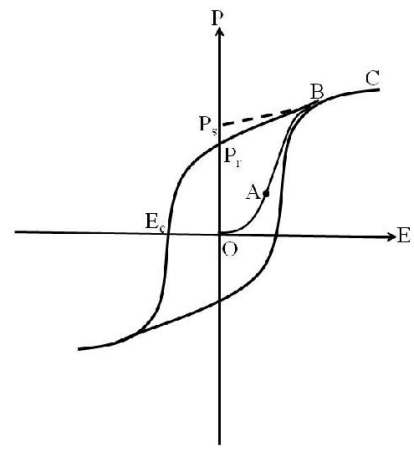

Figure 1 Schematic diagram of hysteresis loop. 
remnant polarization $\left(P_{\mathrm{r}}\right)$. As the material is graded to zero, the reverse electric field strength is called as the coercive field $\left(E_{c}\right)$.

Ferroelectric materials are capable of spontaneous polarization and have a measurable macroscopic electric field inside that can be used as built-in electric field for photovoltaic devices to separate electron-hole pairs and facilitate their transmission. This polarized electric field is the driving force of photocurrent in ferroelectric photovoltaic devices. The dipoles arranged in the ferroelectric material provide a promising way to control the barrier height, the offset of the interface energy or the width of the depletion region, photovoltaic effect of ferroelectric materials (Figure 2). ${ }^{[10-12]}$ This is crucial for all of these ferroelectric materials used in photovoltaic devices. Most of ferroelectric materials not only have the ferroelectric properties, but also absorb light to generate electron-hole pairs.

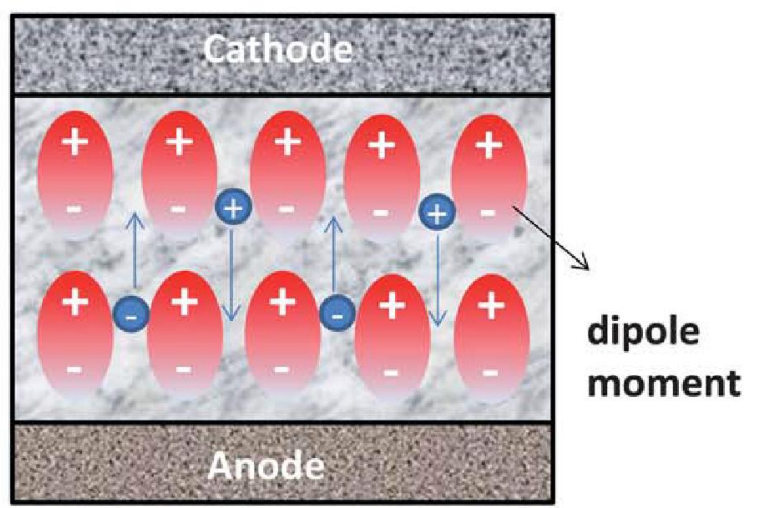

Figure 2 The photovoltaic effect of ferroelectric materials. ${ }^{[12]}$

\section{Ferroelectric Solar Cells}

The overall properties of ferroelectric materials mainly affect the separation of electron-holes and the arrangement of energy bands affecting solar cells. ${ }^{[13]}$ The ideal photovoltaic material should have a band gap of $1.0-1.8 \mathrm{eV}$ that matches the solar spectrum. However, traditional ferroelectrics are usually insulators with large band gap, which has relatively limited light absorption and photocurrent. Therefore, they are not suitable for photovoltaic applications. Zhang et al. ${ }^{[14]}$ reported a new type of ferroelectric material, $\mathrm{KBiFe}_{2} \mathrm{O}_{5}$, which has narrower bandgap $E_{g}=1.6 \mathrm{eV}$. Internal polarization helps to separate photogenerated carriers and enhances the photovoltaic effect, thus having stronger photoelectric activity. The structure of the photovoltaic device is metal electrode/ $/ \mathrm{KBiFe}_{2} \mathrm{O}_{5} /$ metal electrode (Figure 3). This ferroelectric material has higher light absorption leading to higher carrier concentration, which contributes to the conversion of solar energy. Thus, open-circuit photovoltage $\left(V_{\mathrm{oc}}\right)$ and short-circuit photocurrent $\left(J_{\mathrm{sc}}\right)$ are $8.8 \mathrm{~V}$ and $15 \mathrm{~mA} / \mathrm{cm}^{2}$, respectively.

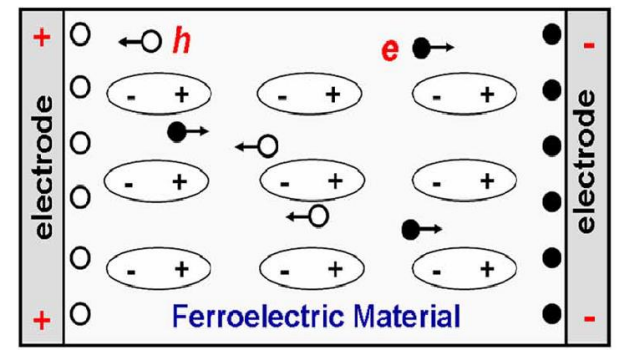

Figure 3 Schematic diagram of the mechanism of photovoltaic device with the structure of metal electrode/ $/ \mathrm{KBiFe}_{2} \mathrm{O}_{5} /$ metal electrode. ${ }^{[14]}$
Most of researches on ferroelectric thin film solar cells focus on the preparation of ferroelectric material thin films. In 2007, Pintilie et al. ${ }^{[15]}$ mainly studied the photovoltaic properties of a sandwich structure of metal/ferroelectric thin films/metal with $\mathrm{Pb}(\mathrm{Zr}, \mathrm{Ti}) \mathrm{O}_{3} \quad(\mathrm{PZT})$ as the ferroelectric layer, and the photoelectric properties conducted by PZT thin films was improved by adjusting the ratio of $\mathrm{Zr}$ and Ti. The Schottky potential existed on the surface of the PZT electrode, so that photocurrent signal could be detected. Then, Cao et al. ${ }^{[16]}$ studied ferroelectric thin film solar cell with the ITO/PZT/Pt structure. In order to improve the photoelectric performance, the $n$-type cuprous oxide $\left(\mathrm{Cu}_{2} \mathrm{O}\right)$ layer was inserted between the PZT thin film and cathode Pt. The $n+-n$ heterojunction of $\mathrm{Cu}_{2} \mathrm{O} / \mathrm{PZT}$ and the Schottky barrier of PZT/ITO provided favorable energy level alignment for efficient extraction of electrons on the electrode. The solar cell achieved $J_{\text {sc }}$ of 4.80 $\mathrm{mA} / \mathrm{cm}^{2}$, and the PCE is increased by 72 times to $0.57 \%$. The ferroelectric solar cells with the structure of glass/ITO/PZT/ a-Si/Ag was prepared. ${ }^{[17]}$ It was found that the solar cell with such a structure facilitated the transmission of electrons photogenerated by ultraviolet visible light, thereby larger $J_{\mathrm{sc}}$ and PCE were obtained. ${ }^{[17]}$ The band gap of PZT ferroelectric film is $3.6 \mathrm{eV}$, a Si film with a narrow band gap (about $1.8 \mathrm{eV}$ ). Although the difference of band gaps between the Si film and the PZT film is large, the Si/PZT heterojunction can effectively enhance the photovoltaic output of solar cells based on ferroelectric PZT films. ${ }^{[17]}$ It has also been found that perovskite-structured methylammonium trihalide thin films has ferroelectric properties, and a novel ferroelectric solar cell was developed based on this structural thin film. The cell structure is $\mathrm{TiO}_{2} / \mathrm{MAPbl}_{3-x} \mathrm{Cl}_{x} / \mathrm{Au}$, which achieved a PCE of $6.7 \%$. The output direction of $V_{o c}$ and $J_{\mathrm{sc}}$ of the cell changed according to the polarization direction of the ferroelectric thin film. In addition, the maximum $V_{\text {oc }}$ obtained by the cell depended on the coercive field of the ferroelectric materials. ${ }^{[18]}$

\section{Ferroelectric-Semiconductor Photovoltaics}

Since the cell prepared by the ferroelectric materials could obtain large $V_{\text {oc }}$, the cell prepared by the semiconductor materials could obtain large $J_{\mathrm{sc}}$, the combination of two materials has attracted extensive research interest. The ferroelectric $\mathrm{BaTiO}_{3}$ thin films with tens of nanometers thickness could be used in the solar cell to have photovoltaic response, and the bulk photovoltaic effect measurement of the film reveals an increase in the photonic field and PCE, so $\mathrm{BaTiO}_{3}$ was received extensive attention. ${ }^{[19]}$ Wang et al. ${ }^{[20]}$ studied ferroelectric material $\mathrm{BaTiO}_{3}$ that was introduced into $\mathrm{Si}$ semiconductor material. In this solar cell, $\mathrm{BaTiO}_{3}$ with field effect could separate carriers generated by silicon substrate to generate electricity. In addition, theoretical studies have shown that the electric field generated by the polarization of $\mathrm{BaTiO}_{3}$ could diffuse into the silicon base, and the adjustment of relevant parameters could optimize the electric field, thereby improving the photoelectric performance of the solar cell.

Immediately after, Liu et al. ${ }^{[21]}$ studied the use of conventional semiconductor material silicon with good capability of carrier transport as the light absorbing layer. They deposited a layer of $\mathrm{BaTiO}_{3}$ on the semiconductor to provide an external electric field for separating carriers generated by the $\mathrm{Si}$ (Figure 4). This ferroelectric material in silicon solar cells without $p-n$ junction was not used for light absorption and provided only external electric field. The anode and the cathode on the semiconductor layer after the $\mathrm{BaTiO}_{3}$ polarization collected electrons and holes, respectively. The electrons are combined with the holes at the cathode through the external circuit to form complete loop. 


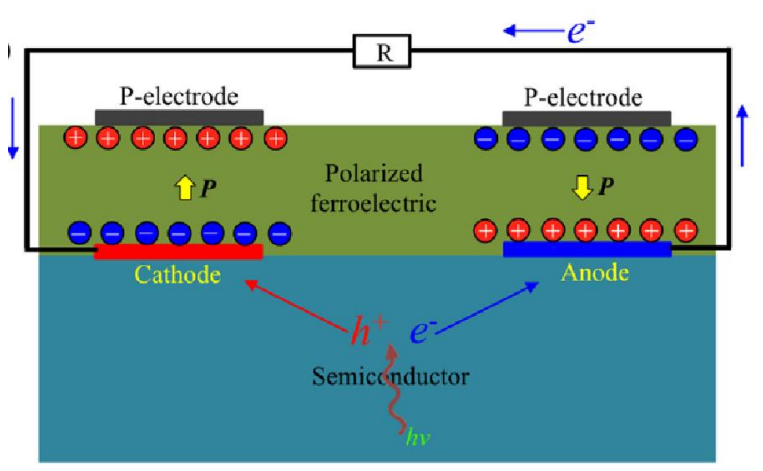

Figure 4 Structure diagram of the $\mathrm{Si} / \mathrm{BaTiO}_{3}$ solar cell. ${ }^{[21]}$

\section{Dye-Sensitized Solar Cells Based on Ferroelectric Materials}

Dye-sensitized solar cells (DSSCs) have attracted much attention due to their low cost, no pollution to the environment, extensive materials to fabricate solar cell. In 1999, Grätzel et al. ${ }^{[22]}$ synthesized mesoporous nanoparticles $\mathrm{SiTiO}_{3}$ by improving the reported method and prepared thin films deposited on conductive glass in dye-sensitized solar cells. It was found that $V_{\text {oc }}$ of the cell based on $\mathrm{SiTiO}_{3}$ is $100 \mathrm{mV}$ higher than that of the cell based on $\mathrm{TiO}_{2}$. For lower $J_{\text {sc }}$ and IPCE, the surface of $\mathrm{SrTiO}_{3}$ selectively changed first by $\mathrm{pH}$ treatment, thereby enhancing the adsorption of dyes and improving the $J_{\mathrm{sc}}$ and IPCE, which provided basis for further optimizing the performance of dye-sensitized solar cells.

$\mathrm{BaTiO}_{3}$ is a ferroelectric material that has been widely used in cells for several years. Zhong et al. ${ }^{[23]}$ mainly studied the application of $\mathrm{BaTiO}_{3} / \mathrm{TiO}_{2}$ (4) electrode in dye-sensitized solar cells. It was found that DSSCs with $\mathrm{BaTiO}_{3} / \mathrm{TiO}_{2}$ (4) electrode has higher PCE than that based on the conventional $\mathrm{TiO}_{2}$ electrode. Because $\mathrm{BaTiO}_{3}$ is a high dielectric ferroelectric material (although it has the similar structure with $\mathrm{TiO}_{2}$ ), the electron lifetime of DSSCs with $\mathrm{BaTiO}_{3} / \mathrm{TiO}_{2}$ (4) electrode was significantly improved, and the recombination reaction at the $\mathrm{TiO}_{2}$ photoelectrode/electrolyte interface was reduced. The interface charge recombination was reduced, so that solar cells with better photovoltaic performance were obtained.

Yu et al.$^{[24]}$ synthesized pure phase perovskite-type $\mathrm{SrTiO}_{3}$, $\mathrm{CaTiO}_{3}$ and $\mathrm{BaTiO}_{3}$ powders by the solid phase reaction. The thin films were prepared to be used in DSSCs. It was found that the cells prepared by the three products obtained higher $V_{o c}$ than the cell based on the pure $\mathrm{TiO}_{2}$. The higher $V_{\text {oc }}$ is due to the fact that the difference between the Fermi level of the oxide and the redox potential of the electrolyte could be larger than that for $\mathrm{TiO}_{2}$. From another aspect, they prepared $\mathrm{TiO}_{2} / \mathrm{SrTiO}_{3}$ and $\mathrm{TiO}_{2} / \mathrm{BaTiO}_{3}$ composite electrodes for DSSCs. When the doping of $\mathrm{SrTiO}_{3}$ and $\mathrm{BaTiO}_{3}$ reached $30 \%$, the highest PCE was achieved, which is more efficient than the cell constructed by pure $\mathrm{TiO}_{2}$. In 2015 , Yu et al. ${ }^{[25]}$ continued to study DSSCs constructed with $\mathrm{TiO}_{2}$ as the first layer, $\mathrm{SrTiO}_{3}$ or $\mathrm{BaTiO}_{3}$ as the second mesoporous double-layer electrode. The electrode constructed by the mesoporous structure of $\mathrm{SrTiO}_{3}$ and $\mathrm{TiO}_{2}$ could increase the adsorption amount of dye. Since $\mathrm{SrTiO}_{3}$ or $\mathrm{BaTiO}_{3}$ was deposited on the upper layer of $\mathrm{TiO}_{2}$ (Figure 5), the electron-hole recombination at the interface between the first layer and the second layer could be suppressed. In addition, the conduction band of $\mathrm{SrTiO}_{3}$ and $\mathrm{BaTiO}_{3}$ is more negative than that of $\mathrm{TiO}_{2}$, and the matching of band structure improved the electron lifetime. Both of these aspects could improve $V_{o c}$ and PCE of the solar cell.

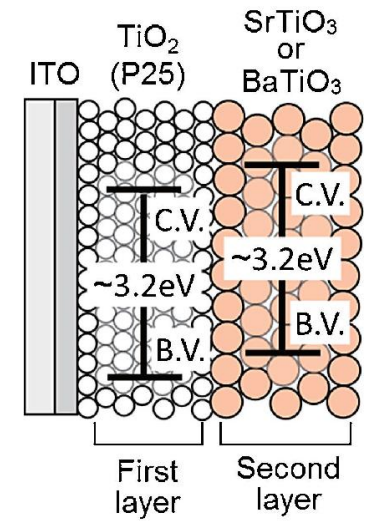

Figure 5 Schematic illustration of the double-layer electrode. $^{[25]}$

Xie et al. ${ }^{[26]}$ fabricated composite structure of $\mathrm{BaTiO}_{3}$ ferroelectric material and $\mathrm{TiO}_{2}$ as photoanode, and the remnant polarization of the composite thin film was $105 \mu \mathrm{C} / \mathrm{cm}^{2}$, indicating that $\mathrm{BaTiO}_{3} / \mathrm{TiO}_{2}$ (4) still has very good ferroelectric performance. In the composite structure, $\mathrm{BaTiO}_{3}$ provided polarized electric field, and $\mathrm{TiO}_{2}$ encapsulated in the outer layer received electrons generated by the light-exciting dye and provided the path of electron transport. The polarization of the $\mathrm{BaTiO}_{3}$ thin films enhanced the adsorption interaction of dye in the cell. The cell has $J_{\mathrm{sc}}$ of $14.44 \mathrm{~mA} / \mathrm{cm}^{2}$ and PCE of $7.29 \%$. The report of this work led to the study of the use of ferroelectric materials in photoelectric devices to improve their performance and deepen the understanding of charge transport and photovoltage generation mechanisms.

\section{Perovskite Solar Cells Based on Ferroelectric Materials}

$\mathrm{BiFeO}_{3}$ is a typical ferroelectric thin film material, and $\mathrm{BiFeO}_{3}$ crystal has photoelectric and photoconductive properties when it is in contact with gold electrode. It has been reported that polycrystalline $\mathrm{BiFeO}_{3}$ ferroelectric thin film material was deposited on conductive glass substrate by the chemical solvent DMF modification method, and the modified $\mathrm{BiFeO}_{3}$ thin films as light absorbing material could absorb more visible light and has narrower band gap. ${ }^{[27,28]}$ Liao et al. ${ }^{[29]}$ found that (benzylammonium) ${ }_{2} \mathrm{PbCl}_{4}$ is a ferroelectric and has ferroelectric properties. At the same time, different metal cations and halides in the perovskite could be adjusted to change the band gap for using in the photovoltaic field. It provided new methods and ideas for the development of new ferroelectric semiconductors. In 2015, Chen et al. ${ }^{[0]}$ proved that $\mathrm{CH}_{3} \mathrm{NH}_{3} \mathrm{Pbl}_{3}$ has ferroelectric properties. In the solar cell composed of perovskite as light absorbing material, when positive electrode electric field was applied on the electrode, the arrangement of ferroelectric domains was arranged in the preferred direction to make the separation and rush through of photogenerated electrons, moreover, the cell obtained the highest PCE and $J_{\mathrm{sc}}$ under the condition of $+2 \mathrm{~V}$ polarization. Subsequent control experiments further showed that the polarization and scanning direction also showed significant impact on the photovoltaic performance of $0.25 \mathrm{BaTiO}_{3}-$ $0.75 \mathrm{BiFeO}_{3}$ ferroelectric solar cells. This indicated the prevalence and universality of this behavior in solar cells based on ferroelectric materials. The application of ferroelectric materials provides a new perspective for adjusting the working mechanism and photovoltaic performance of perovskite solar cells.

Morris et al. ${ }^{[31]}$ used transient absorption spectroscopy (TAS) to study the carrier kinetics of $\mathrm{BaTiO}_{3}$ ferroelectric materials. In 
the absence of applied electric field, the dipoles presenting inside of $\mathrm{BaTiO}_{3}$ could prevent electron-hole recombination and obtained longer lifetimes carriers, which proved that ferroelectric materials are indeed important for improving the PCE of solar photovoltaic devices. Okamoto et al. ${ }^{[32]}$ studied the application of $\mathrm{BaTiO}_{3} / \mathrm{TiO}_{2}$ as double mesoporous electron transport layer in perovskite solar cells. By comparing the effects of different thicknesses of $\mathrm{BaTiO}_{3}$ thin films on the photovoltaic performance of cells, it was found that PCE increased from $9.89 \%$ of the $\mathrm{TiO}_{2}$ mesoporous monolayer to $12.4 \%$, when two layers of $\mathrm{BaTiO}_{3}$ were spin-coated to form the structure (Figure 6). The crystal size of $\mathrm{CH}_{3} \mathrm{NH}_{3} \mathrm{Pbl}_{3}$ on the double mesoporous layer is usually larger, while the larger $\mathrm{CH}_{3} \mathrm{NH}_{3} \mathrm{Pbl}_{3}$ crystal could absorb light and improve the photocurrent, thereby enhancing the photovoltaic performance of the solar cell.

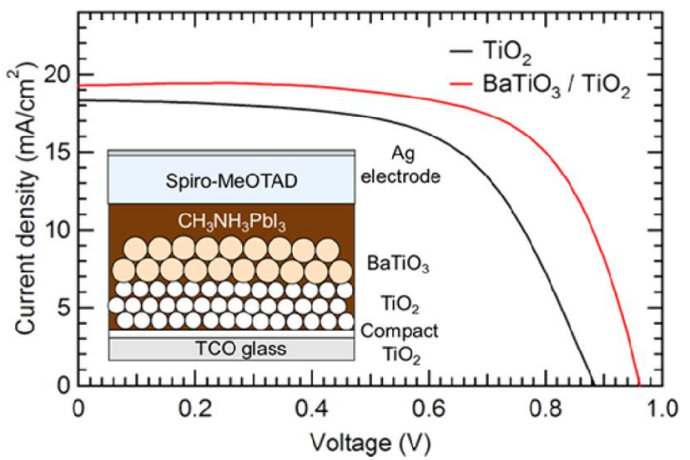

Figure $6 \mathrm{~J}-\mathrm{V}$ curves of solar cells with the structure diagram as shown in inset. ${ }^{[32]}$

\section{Organic Solar Thin Film Solar Cells Based on Ferroelectric Materials}

Yang et al. ${ }^{[33]}$ embedded poly(vinylidenefluoride- trifluoroethylene) (P(VDFTrFE) in organic solar cell (substrate/ITO/ PEDOT:PSS/P ${ }_{3} \mathrm{HT} / \mathrm{P}(\mathrm{VDF}-\mathrm{TrFE}) / \mathrm{PCBM} / \mathrm{Al}$ ). The polarizing layer film could adjust the LUMO difference between the donor and the acceptor and reduce the LUMO energy level difference to optimum value, which is beneficial to electron transport. After the ferroelectric thin film was forward polarized, $V_{\mathrm{oc}}$ and $J_{\mathrm{sc}}$ of the cell were $0.67 \mathrm{~V}$ and $9.0 \mathrm{~mA} / \mathrm{cm}^{2}$, respectively. Therefore, both $V_{\mathrm{oc}}$ and $J_{\mathrm{sc}}$ of the cell could be improved.

Then, Asadi et al. ${ }^{[34]}$ studied the organic solar cells doped with ferroelectric thin films, and compared the cells of P(VDF-TrFE), TrFE, and LiF. After a series of optimized tests, it was found that all three materials contained fluoride. It was speculated that this substance should play an important role in cell performance. Through this study, it was learned that the introduction of $\mathrm{P}(\mathrm{VDF}-\mathrm{TrFE})$ ferroelectric materials into the solar cells was mainly due to the fluoride inside the materials. Xiao et al. ${ }^{[35]}$ prepared $\mathrm{P}(\mathrm{VDF}-\mathrm{TrFE})$ nanoparticles by the solution chemistry and applied them to ferroelectric organic photovoltaic devices. The cell structure is ITO/PEDOT:PSS /PCDTBT:PC70BM/P(VDF-TrFE)/AI. By adjusting the size of $P(V D F-T r F E)$ NPs and the crystallinity of the crystal to control the coverage of the intermediate layer of the ferroelectric thin films, PCE of the cell could be improved. After P(VDF-TrFE) thin film was forward polarized, the photovoltaic performance parameters of the device were greatly improved. Moreover, $V_{\mathrm{oc}}$, $J_{\text {sc }}$ and PCE of the cell were $0.91 \mathrm{~V}, 11.3 \mathrm{~mA} / \mathrm{cm}^{2}$ and $6.64 \%$, respectively. The applications of ferroelectric materials provide a new perspective for adjusting the working mechanism and photovoltaic performance of perovskite solar cells.

\section{Conclusions and Perspectives}

Ferroelectric materials have attracted extensive attention due to their special photoelectric conversion mechanism. Since the ferroelectric solar cells show large $V_{o c}$ and the semiconductor solar cells usually give large $J_{\mathrm{sc}}$, the combination of the two materials will attracted extensive research interest. Some of ferroelectric materials have the properties of semiconductors, so they can be used as light absorbing materials in ferroelectric solar cells to generate electron-hole pairs. At the same time, some of ferroelectrics can be spontaneously polarized and make measurable macroscopic electric field inside, which can separate electron-hole pairs and promote their transmission. These ferroelectric materials can accelerate the transport rate of electron-holes, therefore, ferroelectrics will be widely introduced as different functional structures in semiconductor solar cells to improve the photoelectric performance of these cells. In addition, in perovskite ferroelectric materials, different metal cations and halides could be adjusted to change their band gap for using in the photovoltaic field. It provided new methods and ideas for the development of new ferroelectric semiconductors used in solar cells. Rational introduction of ferroelectric material structure in solar cells opens a new way to further improve their photovoltaic performance.

\section{Acknowledgement}

This work was financially supported by the National Natural Science Foundation of China (No. 21975183), the Natural Science Foundation of Tianjin (No. 14JCYBJC18000) and the Program for Innovative Research Team in Tianjin University (No. TD13-5074)

\section{Conflict of Interest}

The authors declare no conflict of interest.

Copyright (@ 2020 Xinshu Luo, Shixin Xue, and Jingbo Zhang. This article is an open access article distributed under the terms and conditions of the Creative Commons Attribution (CC BY) license (http://creativecommons.org/licenses/by/4.0/). The use, distribution or reproduction in other forums is permitted, provided the original author(s) or licensor are credited and that the original publication in this journal is cited, in accordance with accepted academic practice. No use, distribution or reproduction is permitted which does not comply with these terms.

\section{References}

[1] Amponsah, N. Y.; Troldborg, M.; Kington, B.;.Aalders, I.; Hough, R. L. Renew. Sust. Energ. Rev. 2014, 39.

[2] Khojasteh, D.; Khojasteh, D.; Kamali, R.; Beyene, A.; Iglesias, G. Renew. Sust. Energ. Rev. 2018, 81, 2.

[3] Gooch, D. J. Int. Mater. Rev. 2000, 45, 1

[4] Hansen, K.; Mathiesen, B. V. Sol. Energy 2018, 169.

[5] Green, M. A.; Emery, K.; Hishikawa, Y.; Warta, W.; Dunlop, E. D. Prog. Photovoltaics 2012, 20, 1.

[6] Stuckelberger, M.; Biron, R.; Wyrsch, N.; Haug, F. J.; Ballif, C. Renew. Sust. Energ. Rev. 2017, 76.

[7] Yuan, Y.; Xiao, Z.; Yang, B.; Huang, J. J. Mater. Chem. A 2014 2,17 .

[8] Fousek, J. In Joseph Valasek and the Discovery of Ferroelectricity, Proceedings of 1994 IEEE International Symposium on Applications of Ferroelectrics, 9th, Pennsylvania, America, 1994, $p$. $1-5$.

[9] Kreisel, J.; Alexe, M.; Thomas, P. A. Nat. Mater. 2012, 11, 4

[10] Pintilie, L.; Vrejoiu, I.; Rhun, G. L.; Alexe, M. J. Appl. Phys. 2007, 
$101,6$.

[11] Li, X. D.; Wang, X. M.; Peng, L. P.; Zhang, K. B.; Wu, W. D.; Tang, Y. J. Ferroelectrics 2016, 500, 1.

[12] Yuan, Y. B.; Xiao, Z. G.; Yang, B.; Huang, J. S. J. Mater. Chem. A 2014, 2, 17

[13] Butler, K. T.; Frost, J. M.; Walsh, A. Energ. Environ. Sci. 2015, 8, 3.

[14] Zhang, G. H.; Wu, H.; Li, G. B.; Huang, Q. Z.; Yang, C. Y.; Huang, F. Q.; Liao, F. H.; Lin, J. H. Sci. Rep. 2013, 3, 1723.

[15] Pintilie, L.; Vrejoiu, I.; Rhun, G. L.; Alexe, M. J. Appl. Phys. 2007, $101,6$.

[16] Cao, D. W.; Wang, C. Y.; Zheng, F. G.; Dong, W.; Fang, L.; Shen, M. R. Nano Lett. 2012, 12, 6.

[17] Zheng, F. G.; Xin, Y.; Huang, W.; Zhang, J. X.; Wang, X. F.; Shen, M. R.; Dong, W.; Fang, L.; Bai, Y. B.; Shen, X. Q.; Hao, J. H. J. Mater. Chem. A 2014, 2, 5.

[18] Chen, B.; Shi, J.; Zheng, X. J.; Zhou, Y.; Zhu, K.; Priya S. J. Mater. Chem. A 2015, 3, 15.

[19] Zenkevich, A.; Matveyev, Yu.; Maksimova, K.; Gaynutdinov, R.; Tolstikhina, A.; Fridkin, V. 2014, 90, 16.

[20] Wang, W. T.; Liu, F. D.; Lau, C. M.; Wang, L.; Yang, G. D.; Zheng, D. W.; Li, Z. G. Appl. Phys. Lett. 2014, 104, 12.

[21] Liu, F.; Wang, W. T.; Wang, L.; Yang, G. D. J. Appl. Phys. 2014, 104, 10.

[22] Burnside, S.; Moser, J. E.; Brooks, K.; Grätzel, M.; Cahen, D. J Phys. Chem. B 1999,103, 43.

[23] Zhong, M.; Shi, J. Y.; Zhang, W. H.; Han, H. X.; Li, C. Mater. Sci. Eng. B-ADV 2011, 176, 14.
[24] Okamoto, Y.; Suzuki, Y. J. Ceram. Soc. Jpn. 2014, 122, 1428.

[25] Okamoto, Y.; Suzuki, Y. J. Ceram. Soc. Jpn. 2015, 123, 1442.

[26] Xie, D. M.; Lin, Y.; Fu, N. Q.; Ma, P.; Zhou, X. W. J. Mater. Chem. A 2018, 6, 47.

[27] Dong, W.; Guo, Y. P.; Guo, B.; Liu, H. Y.; Li, H.; Liu, H. Z. Mater Lett. 2012, 88.

[28] Moubah, R.; Rousseau, O.; Colson, D.; Artemenko, A.; Maglione, M.; Viret, M. Adv. Funct. Mater. 2012, 22, 22.

[29] Liao, W. Q.; Zhang, Y.; Hu, C. L.; Mao, J. G.; Ye, H. Y.; Li, P. F.; Huang, S. P. D.; Xiong, R. G. Nat. Commun. 2015, 6, 7338.

[30] Chen, B.; Zheng, X.; Yang, M.; Zhou, Y.; Kundu, S.; Shi, J.; Zhu, K.; Priya, S. Nano Energy 2015,13.

[31] Morris, M. R.; Pendlebury, S. R.; Hong, J.; Dunn, S.; Durrant, J. R. Adv. Mater. 2016, 28, 33.

[32] Okamoto, Y.; Suzuki, Y. J. Phys. Chem. C 2016, 120, 26.

[33] Yang, B.; Yuan, Y. B.; Sharma, P.; Poddar, S.; Korlacki, R.; Ducharme, S.; Gruverman, A.; Saraf, R. F.; Huang, J. S. Adv. Mater. 2012, 24, 11.

[34] Asadi, K.; de Bruyn, P.; Blom, P. W. M.; de Leeuw, D. M. Appl. Phys. Lett. 2011, 98, 18.

[35] Xiao, Z. G.; Dong, Q. F.; Sharma, P.; Yuan, Y. B.; Mao, B. D.; Tian, W. J.; Gruverman, A.; Huang, J. S. Adv. Energy Mater. 2013, 3, 12.

Received November 29, 2020

Accepted December 27, 2020 